\title{
IMPLEMENTASI DISCHARGE PLANNING DENGAN PENDEKATAN FAMILY CENTERED NURSING TERHADAP MOTIVASI KELUARGA DI RUMAH SAKIT PENDIDIKAN UNIVERSITAS HASANUDDIN MAKASSAR
}

\author{
Dina Mariana L. ${ }^{*}$, Rahman Kadir ${ }^{2}$, Kadek Ayu Erika ${ }^{3}$ \\ ${ }^{1}$ Staf Pengajar Keperawatan FK Universitas Sam Ratulangi' \\ ${ }^{2}$ Staf Pengajar Manajemen FE Universitas Hasanuddin \\ ${ }^{3}$ Staf Pengajar FKep Universitas Hasanuddin \\ *) dinamariana@unsrat.ac.id
}

\begin{abstract}
This study aims to analyse the implementation of discharge planning with family centered nursing approach in relation with motivation of families to take care of inpatients at Hasanuddin University Teaching Hospital in Makassar. The research used a post test only with control group design. There were thirty samples selected using the accidental sampling technique. The instruments were discharge planning sheets for the independent variables, and questionnaires and checklists for the dependent variables. The independent $t$ test was used to find out the difference between the interval and the control groups. The results revealed that the independent $t$ test showed a value of $p=0.786$. It means that there is no significant difference between the intervention group (with discharge planning) and the control group (without discharge planning) in terms of motivation. Nevertheless, result of this study concludes that discharge planning with family centered nursing approach applied from the first day of admission to hospital for patients in need of treatment starts from the first entrance to the hospital until the time to get out of the hospital.
\end{abstract}

Keywords: discharge planning, family motivation, family centered nursing

\section{ABSTRAK}

Penelitian ini bertujuan untuk melihat penerapan discharge planning dengan pendekatan family centered nursing terhadap motivasi keluarga dalam merawat pasien rawat inap di Rumah Sakit Pendidikan Universitas Hasanuddin. Penelitian ini menggunakan posttest only with control group design dengan teknik "accidental sampling" sebanyak 30 orang dengan menggunakan instrumen (media) lembar discharge planning untuk variabel independen dan lembar kuesioner dan checklist untuk variabel dependen. Uji statistik $t$ independen digunakan untuk melihat perbedaan antara kelompok interval dan kontrol. Hasil penelitian uji $t$ independen diperoleh $p=0,786$ yang berarti tidak terdapat perbedaan rerata motivasi yang bermakna antara kelompok intervensi yang diberikan discharge planning dengan kelompok kontrol yang tidak diberikan discharge planning. Meskipun demikian, hasil penelitian ini berkesimpulan bahwa discharge planning dengan pendekatan family centered nursing mutlak diterapkan sejak hari pertama pasien masuk ke rumah sakit karena pasien membutuhkan perawatan mulai dari pertama masuk ke rumah sakit hingga keluar dari rumah sakit.

Kata Kunci: discharge planning, motivasi keluarga, family centered nursing

\section{PENDAHULUAN}

Terjadinya

pembangunan kesehatan khususnya teknologi di bidang kesehatan, mempengaruhi pola penyakit dalam masyarakat dimana terjadi perubahan dari penyakit infeksi menjadi penyakit tidak menular dan degeneratif, seperti penyakit jantung, kanker, stroke, dan diabetes melitus. Perubahan tersebut terjadi karena adanya perubahan gaya hidup dan perilaku masyarakat (Rahajeng, 2011).

Penyakit tidak menular menjadi penyebab utama kematian secara global. Berdasarkan data dari World Health Organization (WHO) menjelaskan bahwa 57 juta kematian yang terjadi di dunia pada tahun 2008, sebanyak 36 juta atau hampir dua pertiganya disebabkan oleh penyakit tidak menular (Kemenkes RI, 2012).

Di Indonesia sendiri, berdasarkan dari hasil Riskesdas 2007 menggambarkan bahwa proporsi angka kematian penyakit tidak menular meningkat dari $41,7 \%$ pada tahun 1995 menjadi $59,5 \%$ pada tahun 2007. Selain itu, berdasarkan hasil wawancara dinyatakan bahwa telah terjadi peningkatan prevalensi hipertensi dari 7,6 persen tahun 2007 menjadi 9,5 persen tahun 2013. Hal yang sama juga berlaku untuk stroke dimana berdasarkan wawancara juga meningkat dari 8,3 per 1000 (2007) menjadi 12,1 per1000 (2013). Demikian juga untuk diabetes melitus yang berdasarkan wawancara juga terjadi peningkatan dari 1,1 persen (2007) menjadi 2,1 persen (2013). Kecenderungan 
prevalensi cedera juga menunjukkan sedikit kenaikan dari 7,5 persen (RKD 2007) menjadi 8,2 persen (RKD 2013), dengan penyebab cedera terbanyak yaitu jatuh $(40,9 \%)$ dan kecelakaan sepeda motor $(40,6 \%)$ (Riskesdas, 2013). Peningkatan yang hampir sama pada pasien trauma juga terjadi di RS Universitas Hasanuddin dari tahun ke tahun yaitu sebesar $6 \%$ menjadi $10 \%$, dengan penyebab cedera karena kecelakaan sepeda motor dan terjatuh. Sementara untuk pasien diabetes melitus sendiri jumlah pasien dari tahun ke tahun hampir sama yaitu sekitar $10 \%$ per tahunnya (RS. Unhas, 2016).

Peran utama perawat terhadap keluarga pasien yaitu mampu mengidentifikasi kebutuhan akan discharge planning yang sesuai dengan kebutuhan perawatan pasien saat di rumah, memberikan informasi yang dibutuhkan, serta mendorong keluarga untuk lebih efektif dalam melaksanakan perannya pada pasien (Rasyid and Soertidewi, 2011).

Perencanaan pulang atau discharge planning merupakan bagian dari proses pelayanan keperawatan yang secara sistematis berfungsi untuk menilai, menyiapkan, dan melakukan koordinasi dengan fasilitas kesehatan yang telah ditentukan dengan pelayanan sosial yang terdapat di komunitas, sebelum dan sesudah pasien pindah atau pulang (Rusmita, 2010).

$$
\text { Discharge planning ini }
$$

menempatkan perawat pada posisi yang penting dalam proses pengobatan pasien, dimana perawat berperan dalam mengkaji setiap pasien dengan mengumpulkan dan menggunakan data yang berhubungan untuk mengidentifikasi masalah aktual dan potensial, menentukan tujuan yang akan dicapai bersama pasien dan keluarganya, memberikan tindakan khusus dalam mengajarkan dan mengkaji secara individu dalam mempertahankan atau memulihkan kembali kondisi pasien secara optimal, serta mengevaluasi kesinambungan asuhan keperawatan. Dalam hal ini, perawat dianggap sebagai seseorang yang memiliki kompetensi lebih dan punya keahlian dalam melakukan pengkajian secara akurat, mengelola dan memiliki komunikasi yang baik dan menyadari setiap kondisi dalam masyarakat (Pemila, no date).

Discharge planning yang dilakukan sejak dini akan memberikan dampak yang positif pada pasien, seperti terjadi pemendekan lamanya perawatan pasien di rumah sakit, penurunan anggaran biaya rumah sakit, menurunkan angka kekambuhan setelah pasien pulang dari rumah sakit, dan dapat memungkinkan intervensi rencana pulang dilakukan secara tepat waktu (Swansburg and Swansburg, 2001). Penelitian yang dilakukan $\mathrm{Pi}-\mathrm{Chu}$ Lin dan kawan-kawan pada pasien fraktur menunjukkan bahwa dengan pemberian discharge planning, pengetahuan perawatan diri pasien pada kelompok eksperimen lebih tinggi dari kelompok kontrol, pemulihan fungsional postdischarge menunjukkan adanya kecenderungan yang lebih baik pada kelompok eksperimen dari pada kelompok kontrol dan QOL (quality of life) pada tiga bulan postdischarge juga lebih baik pada kelompok eksperimen dari pada kelompok kontrol (Lin et al., 2009).

$\mathrm{Di}$ Indonesia semua pelayanan keperawatan di rumah sakit, telah merancang berbagai bentuk format discharge planning, namun discharge planning hanya dipakai dalam bentuk pendokumentasian resume pasien pulang saja, yakni berupa informasi yang disampaikan pada pasien yang akan pulang seperti intervensi medis dan non medis yang sudah diberikan, jadwal kontrol, dan kebutuhan gizi yang harus dipenuhi setelah pasien di rumah. Berdasarkan dari hasil observasi dan studi dokumentasi, pelaksanaan discharge planning di Rumah Sakit Pendidikan Universitas Hasanuddin masih belum berjalan sesuai standar yang semestinya. Pemberian discharge planning yang diterapkan di RS. Unhas meliputi informasi yang berkisar tentang waktu kontrol, cara minum obat, pemberian surat rujukan, dan surat sakit. Sedangkan, dari hasil wawancara yang telah dilakukan dengan keluarga pasien, pemberian health education kepada pasien dan keluarga masih bersifat incidental yaitu jika ada pertanyaan dari pasien atau keluarganya saja dan belum dikemas dalam format pendidikan kesehatan yang sesuai dengan kondisi pasien. Sehingga penderita penyakit diabetes melitus masih sering masuk berulang dengan diagnosa yang sama setiap masuk sehingga dapat dikatakan penerapan discharge planning belum dilakukan secara optimal.

Discharge planning yang efektif seharusnya dimulai pada saat pasien mendapatkan pelayanan kesehatan yang diikuti dengan kesinambungan perawatan 
baik dalam proses penyembuhan maupun dalam mempertahankan derajat kesehatannya sampai pasien merasa siap untuk kembali ke lingkungannya. Berdasarkan uraian permasalahan di atas, peneliti tertarik untuk melakukan penelitian tentang "Implementasi Discharge Planning dengan Pendekatan Family Centered Nursing terhadap Motivasi Keluarga dalam Merawat Pasien Rawat Inap di Rumah Sakit Universitas Hasanuddin Makassar".

Adapun tujuan dari penelitian ini adalah untuk melihat penerapan discharge planning dengan pendekatan family centered nursing terhadap motivasi keluarga dalam merawat pasien rawat inap di RS Universitas Hasanuddin.

\section{METODE}

\section{Desain, tempat dan waktu}

Penelitian dilakukan di RS.

Pendidikan Universitas Hasanuddin di ruangan rawat inap kelas I, II, III, dan VIP. Jenis penelitian ini adalah quasi eksperimental dengan pendekatan post test only with control group design atau static group comparison.

\section{Jumlah dan cara pengambilan subjek}

Populasi dalam penelitian ini adalah semua keluarga pasien yang sesuai dengan diagnosa medis (bedah tulang, diabetes melitus, dan pasien post amputasi) yang dirawat di ruangan kelas I, II, III, dan VIP di RS. Pendidikan Universitas Hasanuddin, dengan sampel 30 orang (15 kelompok intervensi dan 15 kelompok kontrol) dengan teknik accidental sampling.

Kriteria inklusi dalam penelitian ini adalah: pasien baru masuk (hari pertama dirawat di ruangan rawat inap) dengan diagnosa medis: bedah tulang (orthopedi), diabetes mellitus, dan pasien post amputasi; keluarga yang sama yang sering ditemui peneliti pada saat penelitian dilakukan dan yang nantinya akan merawat pasien saat di rumah, usia keluarga $\geq 18$ tahun; pendidikan keluarga minimal SMA, anggota keluarga yang memiliki kesadaran komposmentis, dalam keadaan tenang, tidak demensia atau gangguang kognitif; bersedia diteliti dengan menandatangani informed consent. Kriteria eksklusi dalam penelitian ini adalah keluarga dengan latar belakang bidang kesehatan.

Penelitian ini telah disetujui secara etik dari komisi etik penelitian dengan nomor register UH16040262 yang diterima pada tanggan 8 April 2016.

\section{Jenis dan Cara Pengumpulan Data}

Data yang digunakan adalah data primer yang dikumpulkan sendiri oleh peneliti dengan prosedur sebagai berikut: (1) Menetapkan pemilihan responden; (2) Melakukan identifikasi pasien berdasarkan diagnosa medis dan menetapkan responden sesuai dengan kriteria inklusi; (3) Meminta persetujuan responden untuk berpartisipasi dalam penelitian; (4) Melakukan pengkajian pada kelompok intervensi tentang kebutuhan discharge planning; (5) Memberikan discharge planning dengan implementasi khususnya health education pada kelompok intervensi sedangkan pada kelompok kontrol mendapatkan discharge planning dari perawat ruangan sesuai dengan standar yang dijalankan di ruangan tersebut. Pada pertemuan pertama: Pasien dan keluarga diorientasikan terlebih dahulu, membina hubungan saling percaya dan melakukan tahap pengkajian kebutuhan pendidikan kesehatan. Pertemuan kedua: Peneliti memberikan pendidikan kesehatan sesuai dengan kebutuhan pasien yang meliputi pengertian, penyebab, tanda dan gejala, serta faktor risiko pada kelompok intervensi (perlakuan) selama 30 menit dengan metode ceramah dan diskusi. Pertemuan ketiga: Peneliti memberikan promosi kesehatan tentang cara perawatan penyakit yang meliputi pemenuhan kebutuhan ADL pada kelompok perlakuan selama 30 menit dengan metode ceramah, diskusi. Pertemuan keempat: Peneliti melakukan posttest dengan memberikan kuesioner untuk mengukur motivasi dan pengetahuan responden.

\section{Pengolahan dan analisis data}

Analisa data dilakukan dengan program SPSS 16 for Windows dengan menggunakan analisis deskriptif distribusi frekuensi. Uji yang akan digunakan pada penelitian ini yaitu uji $t$ independen jika data berdistribusi normal dan uji mann whitney apabila data berdistribusi tidak normal (Dahlan, 2014).

\section{HASIL}

Penelitian ini dilaksanakan di RS Universitas Hasanuddin pada bulan April sampai Mei 2016. Pengumpulan data dilakukan di 3 ruangan rawat inap yaitu kelas I, kelas II dan III, serta ruangan VIP melalui penyebaran kuesioner yang diisi 
oleh 30 keluarga pasien, dengan 15 kelompok intervensi dan 15 kelompok kontrol.

Tabel 1 menunjukkan bahwa karakteristik responden menurut jenis kelamin antara laki-laki dan perempuan pada kedua kelompok sebagian besar berjenis kelamin perempuan, yakni sebesar $36,4 \%$ pada kelompok intervensi dan $30,3 \%$ pada kelompok kontrol. Dari segi pendidikan, pada kelompok intervensi responden rata-rata berada pada tingkat pendidikan tinggi (S1 dan S2) yaitu sebesar $53,3 \%$ sedangkan pada kelompok kontrol, responden yang terbanyak terdapat pada tingkat pendidikan rendah (SMA dan D3) yaitu sebesar $66,7 \%$. Dari segi pekerjaan, antara kelompok intervensi dan kontrol ratarata adalah wiraswasta dengan persentase sebesar $18,2 \%$ pada kelompok intervensi dan $24,2 \%$ pada kelompok kontrol. Menurut komplikasi yang timbul, pada kedua kelompok umumnya tidak terdapat komplikasi dengan persentase $36,4 \%$ pada kelompok intervensi dan pada kelompok kontrol $30,3 \%$.

Tabel 2 menunjukkan bahwa rata-rata usia responden pada dua kelompok yaitu kelompok intervensi dan kontrol adalah 35,16 tahun dengan standar deviasi 9,32. Usia termuda pada kelompok intervensi 18 tahun dan usia tertua 57 tahun sedangkan pada kelompok kontrol, usia termuda 22 tahun dan usia tertua 49 tahun. Hasil estimasi interval pada kelompok intervensi dapat disimpulkan bahwa $95 \%$ diyakini ratarata usia responden adalah 27,28 sampai 39,52 tahun dan pada pada kelompok kontrol $95 \%$ diyakini rata-rata usia adalah 32,72 sampai 41,14 tahun. Nilai rata-rata lama pasien menderita penyakit pada kelompok intervensi yaitu sebesar 23,20 dan pada kelompok kontrol sebesar 77,67. Lama pasien menderita penyakit (sebelum dibawa ke rumah sakit) yaitu minimal 1 minggu dan paling lama 52 minggu (1 tahun) pada kelompok intervensi dengan estimasi interval yaitu 9,63 sampai 36,77 sedangkan pada kelompok kontrol, pasien menderita penyakit minimal 1 minggu dan paling lama 208 minggu (4 tahun) dengan estimasi interval sebesar 37,97 sampai 117,36 . Jika dilihat dari nilai rata-rata lama pasien diopname, antara kelompok intervensi dan kontrol memiliki nilai yang hampir sama, yakni pada kelompok intervensi sebesar 4,00 dan pada kelompok kontrol sebesar 4,87 . Lamanya hari rawat antara kelompok intervensi dan kontrol juga tidak berbeda jauh, yaitu pada kelompok intervensi pasien diopname selama 1 hingga 7 hari dengan estimasi interval yakni 2,74 hingga 5,26 dan pada kelompok kontrol selama 1 hingga 7 hari dengan estimasi interval yakni 3,98 sampai 5,75 .

Tabel 3 dapat disimpulkan bahwa motivasi responden dalam merawat pasien umumnya tinggi pada kedua kelompok dengan persentase sebesar $53,3 \%$ pada kelompok intervensi dan $66,7 \%$ pada kelompok kontrol. Begitu juga dalam hal kesiapan, responden pada kedua kelompok sudah memiliki kesiapan dalam merawat pasien dengan persentase pada kelompok intervensi lebih besar dari kelompok kontrol yakni sebesar $73,3 \%$.

Tabel 4 dengan menggunakan uji $t$ independent diperoleh nilai $p=0,786$, karena nilai $p>0,05$ maka secara statistik menunjukkan bahwa tidak terdapat perbedaan rerata motivasi yang bermakna antara kelompok kontrol yang tidak diberikan discharge planning dan kelompok intervensi yang diberikan discharge planning.

\section{PEMBAHASAN}

Berdasarkan dari hasil penelitian implementasi discharge planning dengan pendekatan family centered nursing terhadap motivasi keluarga dalam merawat pasien menunjukkan bahwa rata-rata motivasi pada kelompok intervensi sebesar 39,00 dan pada kelompok kontrol sebesar 38,67 dengan nilai $p=0,786$ yang berarti bahwa tidak terdapat perbedaan rerata motivasi yang bermakna antara kelompok intervensi yang diberikan discharge planning dengan kelompok kontrol yang tidak diberikan discharge planning. Hal ini dapat disebabkan karena tidak adanya perbedaan yang signifikan dari variabel perancu yaitu usia, jenis kelamin, pendidikan dari kedua kelompok. Rata-rata usia keluarga pada kedua kelompok berada pada usia dewasa yaitu berkisar antara (1857 tahun). Dari hasil penelitian menunjukkan pada usia dewasa akhir ( $\geq 25$ tahun) cenderung memiliki motivasi yang tinggi dibandingkan usia dewasa awal $1<25$ tahun). Pada kelompok kontrol, jumlah responden yang memiliki motivasi tinggi lebih banyak berada pada usia dewasa akhir yaitu sebanyak 9 orang $(90 \%)$ sedangkan yang berada pada usia dewasa awal hanya 1 orang (10\%), sehingga dapat dikatakan 
$80 \%$ bermakna secara klinis. Pada usia ini, seseorang dikatakan telah memiliki motivasi yang kuat dalam merawat anggota keluarga yang sakit, sehingga antara kelompok intervensi dan kelompok kontrol tidak terdapat perbedaan yang signifikan.

Dari segi faktor pendidikan, antara kelompok intervensi dan kontrol tidak terdapat perbedaan yang signifikan. Responden umumnya tergolong dalam pendidikan menengah ke atas yang telah memiliki motivasi yang sangat baik dalam merawat anggota keluarga yang sakit. Dari hasil penelitian pada kelompok kontrol, pengaruh pendidikan responden terhadap motivasi yang tinggi bermakna $40 \%$ secara klinis. Hal ini sejalan dengan penelitian yang menyatakan bahwa pendidikan menunjukkan tingkat intelegensi yang berhubungan dengan daya pikir dan motivasi seseorang (Susanti, 2013). Sehingga peneliti berpendapat bahwa tingkat pendidikan memiliki pengaruh terhadap motivasi seseorang. Semakin tinggi tingkat pendidikan seseorang, maka semakin luas pengetahuan dan tingkat motivasinya.

Hal tersebut sesuai dengan penelitian yang dilakukan oleh Wurtiningsih (2012) yang menyatakan bahwa anggota keluarga mampu memberikan berbagai bentuk dukungan kepada penderita yaitu berupa dukungan informasional, dukungan emosional, dukungan instrumental, dan dukungan penghargaan. Keluarga umumnya memberikan dukungan emosional dengan merawat penderita. Dukungan instrumental dilakukan dengan memberikan terapi rehabilitasi, sedangkan dukungan penghargaan diberikan dalam bentuk ucapan terima kasih dan perhatian. Dan dengan adanya dukungan tersebut semakin membantu anggota keluarga yang sakit dalam proses penyembuhannya (Wurtiningsih, 2012).

Sehingga kesimpulan yang dapat diambil yakni pemberian discharge planning dengan menggunakan pendekatan keluarga terhadap motivasi sangat berperan penting dalam pemberian proses perawatan dan penyembuhan pasien. Hal tersebut dapat dilihat dari motivasi yang diberikan keluarga untuk pasien sangat mempengaruhi dalam proses kesembuhan, dimana keluarga yang memiliki motivasi yang besar dalam merawat pasien akan mempercepat dalam proses kesembuhan. Motivasi yang diberikan oleh keluarga dapat berupa dukungan emosional, dukungan informasional, dukungan penghargaan yang dimana dengan beberapa dukungan tersebut pihak keluarga dapat memberikan perawatan yang maksimal sehingga mempercepat proses penyembuhan. Motivasi, dan pengetahuan sangat penting dimiliki oleh keluarga dalam membantu proses penyembuhan pasien ketika pulang ke rumah. Sehingga dapat dikatakan bahwa discharge planning dengan pendekatan keluarga sangat bermanfaat untuk mencegah masuknya kembali pasien ke rumah sakit, menurunkan lama tinggal pasien di rumah sakit, serta dapat meningkatkan kualitas hidup pasien.

\section{KESIMPULAN}

Penelitian ini menyimpulkan bahwa tidak terdapat perbedaan penerapan discharge planning dengan pendekatan family centered nursing terhadap motivasi keluarga dalam merawat pasien antara kelompok intervensi dan kelompok kontrol di ruang rawat inap RS Pendidikan Universitas Hasanuddin. Hal ini disebabkan karena tidak adanya perbedaan yang signifikan dari variabel perancu yaitu, usia, jenis kelamin, dan pendidikan dari kedua kelompok.

\section{SARAN}

Disarankan perlunya menerapkan program discharge planning dengan menggunakan pendekatan pada keluarga sehingga keluarga pasien dapat melanjutkan program perawatan, pengobatan dan rehabilitasi setelah sampai di rumah.

\section{UCAPAN TERIMA KASIH}

Peneliti mengucapkan terima kasih kepada pihak-pihak yang telah membantu sehingga penelitian ini dapat terselenggara dengan baik.

\section{DAFTAR PUSTAKA}

Dahlan, S. (2014) Statistik untuk kedokteran dan kesehatan. Edisi 6. Jakarta: Epidemiologi Indonesia.

Kemenkes RI (2012) Buletin jendela data dan informasi kesehatan volume 2.

Lin, P. et al. (2009) 'To evaluate the effectiveness of a dischargeplanning programme for hip fracture patients', Journal of clinical nursing, pp. 1632-1639. doi: 10.1111/j.13652702.2008.02695.x. 
Pemila, U. (no date) Konsep discharge planning.

Rahajeng, E. (2011) Upaya pengendalian penyakit tidak menular di Indonesia: Buletin jendela data \& informasi kesehatan Volume 2.

Rasyid, A. and Soertidewi, L. (2011) Unit stroke: Manajemen stroke secara komprehensif. 2nd edn. Jakarta: Balai Penerbit FKUI.

Riskesdas (2013) 'RISET KESEHATAN DASAR'. Badan Penelitian dan Pengembangan Kesehatan Kementerian Kesehatan RI.

Rusmita, E. (2010) Model perencanaan pulang yang berbasis teknologi informasi di ruang nifas. Universitas Indonesia. Available at: http://pkko.fik.ui.ac.id/.
Susanti, E. N. (2013) Hubungan karakteristik perawat dengan motivasi perawat dalam pemenuhan kebutuhan kebersihan diri pasien di ruang rawat inap RSU dr. H. Koesnadi Bondowoso. Universitas Jember.

Swansburg, R. and Swansburg, L. (2001) Pengembangan staf keperawatan: Suatu komponen pengembangan sumber daya manusia. Edited by M. Ester. Jakarta: EGC.

Wurtiningsih, B. (2012) 'Dukungan keluarga pada pasien stroke di ruang saraf RSUP dr. Kariadi Semarang', Medica Hospitalia, 1(1), pp. 57-59. 
Tabel 1. Distribusi Responden Menurut Karakteristik Jenis Kelamin, Pendidikan, Pekerjaan, Komplikasi di RS Pendidikan Universitas Hasanuddin

\begin{tabular}{|c|c|c|c|c|c|c|}
\hline \multirow[t]{2}{*}{$\begin{array}{c}\text { Karakteristik } \\
\text { Responden }\end{array}$} & \multicolumn{2}{|c|}{$\begin{array}{c}\text { Kelompok Intervensi } \\
(n=15)\end{array}$} & \multirow[t]{2}{*}{ p } & \multicolumn{2}{|c|}{$\begin{array}{c}\text { Kelompok Kontrol } \\
(n=15)\end{array}$} & \multirow[t]{2}{*}{ p } \\
\hline & $\mathrm{n}$ & $\%$ & & $\mathrm{n}$ & $\%$ & \\
\hline $\begin{array}{l}\text { Jenis Kelamin: } \\
\text { Laki-laki } \\
\text { Perempuan }\end{array}$ & $\begin{array}{c}3 \\
12\end{array}$ & $\begin{array}{r}9,1 \\
36,4\end{array}$ & 0,015 & $\begin{array}{c}5 \\
10\end{array}$ & $\begin{array}{l}15,2 \\
30,3\end{array}$ & 0,015 \\
\hline $\begin{array}{c}\text { Pendidikan: } \\
\text { Rendah (SMA \& D3) } \\
\text { Tinggi (S1 \& S2) }\end{array}$ & $\begin{array}{l}7 \\
8 \\
\end{array}$ & $\begin{array}{l}46,7 \\
53,3 \\
\end{array}$ & 0,243 & $\begin{array}{c}10 \\
5 \\
\end{array}$ & $\begin{array}{l}66,7 \\
33,3 \\
\end{array}$ & 0,001 \\
\hline $\begin{array}{c}\text { Pekerjaan: } \\
\text { IRT } \\
\text { Wiraswasta } \\
\text { PNS }\end{array}$ & $\begin{array}{l}5 \\
6 \\
4\end{array}$ & $\begin{array}{l}15,2 \\
18,2 \\
12,1\end{array}$ & 0,446 & $\begin{array}{l}5 \\
8 \\
2\end{array}$ & $\begin{array}{r}15,2 \\
24,2 \\
6,1\end{array}$ & 0,044 \\
\hline $\begin{array}{c}\text { Komplikasi } \\
\text { Tidak ada komplikasi } \\
\text { Ada komplikasi }\end{array}$ & $\begin{array}{c}12 \\
3 \\
\end{array}$ & $\begin{array}{r}36,4 \\
9,1 \\
\end{array}$ & 0,001 & $\begin{array}{c}10 \\
5\end{array}$ & $\begin{array}{l}30,3 \\
15,2 \\
\end{array}$ & 0,001 \\
\hline
\end{tabular}

Sumber: Data primer 2016

Tabel 2. Distribusi Responden Menurut Karakteristik Usia, Lama Pasien Menderita Penyakit, dan Lama Pasien Diopname di RS Pendidikan Universitas Hasanuddin

\begin{tabular}{|c|c|c|c|c|c|c|c|}
\hline & $\begin{array}{c}\text { Karakteristik } \\
\text { Responden }\end{array}$ & Mean & Median & SD & $\begin{array}{l}\text { Min- } \\
\text { Max }\end{array}$ & $95 \% \mathrm{Cl}$ & p \\
\hline \multirow{3}{*}{$\begin{array}{l}\text { Kelompok } \\
\text { Intervensi }\end{array}$} & Usia & 33,40 & 31,00 & 11,04 & $18-57$ & $27,28-39,52$ & 0,513 \\
\hline & $\begin{array}{c}\text { Lama pasien } \\
\text { menderita } \\
\text { penyakit }\end{array}$ & 23,20 & 8,00 & 24,50 & $1-52$ & $9,63-36,77$ & 0,040 \\
\hline & $\begin{array}{l}\text { Lama pasien } \\
\text { diopname }\end{array}$ & 4,00 & 4,00 & 2,268 & $1-7$ & $2,74-5,26$ & 0,002 \\
\hline \multirow{3}{*}{$\begin{array}{l}\text { Kelompok } \\
\text { Kontrol }\end{array}$} & Usia & 36,93 & 39,00 & 7,601 & $22-49$ & $32,72-41,14$ & 0,072 \\
\hline & $\begin{array}{c}\text { menderita } \\
\text { penyakit }\end{array}$ & 77,67 & 52,00 & 71,679 & $1-208$ & $37,97-117,3$ & 0,000 \\
\hline & $\begin{array}{l}\text { Lama pasien } \\
\text { diopname }\end{array}$ & 4,87 & 5,00 & 1,598 & $2-7$ & $3,98-5,75$ & 0,002 \\
\hline
\end{tabular}

Sumber: Data primer 2016

Tabel 3. Distribusi Responden Berdasarkan Variabel Penelitian Motivasi Responden di RS Pendidikan Universitas Hasanuddin

\begin{tabular}{ccccc}
\hline \multirow{2}{*}{ Motivasi } & \multicolumn{2}{c}{ Tinggi } & \multicolumn{2}{c}{ Rendah } \\
\cline { 2 - 5 } & $\mathrm{n}$ & $\%$ & $\mathrm{n}$ & $\%$ \\
\hline $\begin{array}{c}\text { Kelompok } \\
\text { Intervensi }\end{array}$ & 8 & 53,3 & 7 & 46,7 \\
$\begin{array}{c}\text { Kelompok } \\
\text { Kontrol }\end{array}$ & 10 & 66,7 & 5 & 33,3 \\
\hline
\end{tabular}

Sumber: Data primer 2016 
Tabel 4. Perbedaan Penerapan Discharge Planning dengan Pendekatan Family Centered Nursing terhadap Motivasi Keluarga dalam Merawat Pasien pada Kelompok Intervensi di RS Pendidikan Universitas Hasanuddin

\begin{tabular}{ccccc}
\hline $\begin{array}{c}\text { Motivasi keluarga setelah } \\
\text { pemberian discharge planning }\end{array}$ & Mean & SD & $\mathbf{9 5 \%} \mathbf{C l}$ & Nilai p \\
\hline Motivasi intervensi & 39,00 & 3,761 & $\begin{array}{c}-0,333 \\
(-0,28-2,15)\end{array}$ & 0,786 \\
Motivasi kontrol & & & & \\
\hline
\end{tabular}

Uji $t$ independent ${ }^{*}$ 